\title{
Molecular Characterization Of Extended Spectrum Betalactamases Genes (Blactxm And Blashv) In Enterobacteria Isolates In Medical Specimens In Lomé (Togo)
}

Sika Dossim ( $\square$ sikorlaure@gmail.com )

Universite de Lome Faculte des Sciences de la Sante https://orcid.org/0000-0002-1541-229X

Mounerou SALOU

Universite de Lome Faculte des Sciences de la Sante

Majesté IHOU-WATEBA

Universite de Lome Faculte des Sciences de la Sante

Bawisdom BIDJADA

Institut National d'Hygiène de Lomé

Amivi Mawussi GODONOU

Centre Hospitalier Universitaire Sylvanus Olympio de Lomé

Eugene AOUSSI

Institut National d'Hygiène de Lomé

Abiba KERE-BANLA

Institut National d'Hygiène de Lomé

Mireille PRINCE DAVID

Universite de Lome Faculte des Sciences de la Sante

Anoumou Yaotse DAGNRA

Universite de Lome Faculte des Sciences de la Sante

Research article

Keywords: Antimicrobial resistance; ESBL genes; Enterobacteria ; Togo

Posted Date: July 16th, 2019

DOI: https://doi.org/10.21203/rs.2.10678/v1

License: (c) (1) This work is licensed under a Creative Commons Attribution 4.0 International License.

Read Full License 


\section{Abstract}

Background Extendum Bêtalactamases genes spread throughout the world. Many informations are known about it in Europe, Asia and elsewhere. In Africa particularly in Togo, we have lack informations although their prevalence are still increasing. The aim of this study is to identify the blaSHV and blaCTXM genes on Escherichia coli and Klebsiella pneumoniae strains isolated in two medical bacteriology laboratories in Lomé. Material and method 46 strains (20 Klebsiella pneumoniae, 23 Escherichia coli and 3 Enterobacter cloacae) isolated at Sylvanus Olympio Teaching Hospital $(n=31)$ and at Institut d'Hygiène $(n=15)$ in Lomé were investigated in search of blaSHV and blaCTXM through gene amplification. The strains were isolated from various samples in 2015 and 2016. An amplification of blaTEM was carried out in case of negativity to both genes. A sequencing of the amplicons was carried out then the sequences identified through blastX on the basis of NCBI data. Results We found 97.9\% resistance to amoxicillin + clavulanic acid, gentamicin, levofloxacin and to sulfamethoxazole + trimethoprim. $8.7 \%$ of the strains were resistant to ertapenem. All the strains carried blaCTXM-15. In Klebsiella pneumoniae, blaSHV-1 blaSHV-11, blaSHV-28, blaSHV-61, blaSHV-77 were identified. Associations were found (blaSHV-1 / blaCTXM-15, blaSHV-11 / blaCTXM-15, blaSHV-28 / blaCTXM-15). blaTEM was identified on a strain of Enterobacter cloacae. Conclusion There is a diversity of blaSHV genes with a dominance of blaCTXM-15. blaTEM remains the gene to search for in case of absence of the two previous genes in ESBL strains in Lomé.

\section{Background}

Beta-lactams are a class of antibiotic molecules widely prescribed worldwide in various bacterial infections. The resistance of bacteria to antibiotics is a public health issue. Indeed, the development by resistant bacteria especially to this class of antibiotics significantly reduces the therapeutic options. These include the production of extended-spectrum beta-lactamases (ESBL); enzymes which inactivate all cephalosporins and spare only cephamycins and carbapenems are quite frightening. They are quite widespread worldwide because most often their production is mediated by plasmids (1) and remains a concern at the hospital because responsible for healthcare associated infections (2). Most often, we find the enzymes of CTX-M and SHV types in enterobacteria. SHV is a constitutive enzyme in Klebsiella pneumoniae which first SHV-1 was described in 1972 and since,several variants have been described (3). CTX-M remains by far the most described in ESBL (1).

Data on these enzymes exist at the Asian and European levels, however, are lower at the African level and rare at the national level. However, prevalence of ESBL producing bacteria are mentioned across the continent (4-6). In order to have epidemiological data at the national level, we have initiated this work which purpose is to describe the types of CTX-M and SHV carried by clinical strains of enterobacteria in Lomé.

\section{Methods}


ESBL strains were routinely identified and we randomly selected 46 strains (20 Klebsiella pneumoniae, 23 Escherichia coli and 3 Enterobacter cloacae) including 31 strains isolated at Sylvanus Olympio Teaching Hospital (CHUSO) and 15 strains at InstitutNational d'Hygiène (INH).

- Sylvanus Olympio Teaching Hospital (CHUSO) is the reference center of the country and is located in Lomé, the capital city of Togo

- Institut National d'Hygiène (INH) is the national public health laboratory of Lomé.

These two centers are the ones that carry out the most acts of medical bacteriology in Lomé.

A total of 15 strains were isolated in 2015 (3 Klebsiella pneumoniae and 12 Escherichia coli) and the others in 2016. Strains came from various samples (urine, blood culture, pus, vaginal specimen).

\section{Susceptibility testing}

Bacteria were identified for the most part by conventional technique on the basis of their biochemical characters or by API 20E system. They were tested on various antibiotic discsthrough the method of Kirby Bauer and the interpretations made in accordance with the recommendations of the CA-SFM 2015 (Antibiogram Committee ofFrench Society for Microbiology). The antibiotics tested were: beta-lactams (amoxicillin, amoxicillin + clavulanic acid, ticarcillin, ticarcillin + clavulanic acid, cefoxitin, cefotaxime, cefepime, ceftriaxone, imipenem, ertapenem); monobactams (aztreonam), aminoglycosides (gentamycin, amikacin); quinolones (levofloxacin); sulfadoxine-pyrimethamine; fosfomycin.

They were labeled carriers of ESBL in presence of synergy between amoxicillin+ clavulanic acid discs and aztreonam or between amoxicillin+ clavulanic acid and one of the third generation cephalosporin discs.

\section{Molecular Characterisation of ESBL genes}

The DNA was extracted by boiling extraction from an isolated colony suspended in $100 \mu$ lof water at $95^{\circ}$ $C$ for 15 minutes followed by a centrifugation step. The $b / a_{\text {CTXM }}$ and $b / a_{\text {SHV }}$ genes were identified through gene amplification using well defined primers(SHV-A: 5'-atg-cgt-tat-wtt-cgc-ctg-tgt-3 '; SHV-B : 5'-tta-gcgttg-cca-gtg-ctc-g-3'; CTXM-A : 5'-scs-atg-tcg-agy-acc-agt-aa-3'; CTXM-B : 5'- ccg-cra-tat-grt-tgg-ttg-tg3' ; TEM-1 : 5'-gta-tcc-gct-cat-gag-aca-ata-3' ; TEM-2 : 5'-tct-aaa-gta-tat-atg-agt-aaa-ctt-ggt-ctg-3')according to the following program: $95^{\circ} \mathrm{C}$ for $3 \mathrm{~min}, 95^{\circ} \mathrm{C}$ for $30 \mathrm{~s}, 55^{\circ} \mathrm{C}$ for $30 \mathrm{~s}, 72^{\circ} \mathrm{C}$ for 60 seconds, then $72{ }^{\circ} \mathrm{C}$ for 7 minutes with $50 \mu \mathrm{l}$ of reaction mixture $(25 \mu \mathrm{l}$ of GreenTaq, $2.5 \mu \mathrm{l}$ of each primer; $18 \mu \mathrm{l}$ of $\mathrm{H} 2 \mathrm{O}$ and $2 \mu \mathrm{l}$ of DNA extract). The search for bla $a_{\mathrm{SHV}}$ was carried out only on the strains of $K$. pneumoniae, that of bla $a_{\mathrm{CTXM}}$ on all the strains without any exception. The gene amplification of bla $\mathrm{TEM}_{\mathrm{TEM}}$ was carried out only in case of negativity to the two desired genes. The primers used were (TEM-1: 5'-gta-tcc-gct-cat-gag-aca-ata-3 '; TEM2: 5'-tct-aaa-gta-tat-atg-agt-aaa- ctt-ggt-ctg-3 '). For all the desired genes, the gene amplification was done over 30 cycles. Positive controls for each gene were used as controls. The products of amplification were 
revealed by a UV reader after electrophoretic migration on a $1 \%$ agarose gel using ethidium bromide as intercalating agent. The migration was performed over 60 minutes at $100 \mathrm{~V}$ with a $100 \mathrm{bp}$ size marker (Promega, USA).

\section{Sequencing}

All the positive amplicons were purified by a Quiagen Kit, QIAquick PCR Purification Kit (Roche laboratories) and a sequencing PCR for each primer was performed with a $10 \mu$ ltotal mix (2 $\mu$ lof Big Dye, $3 \mu$ l of primer $1 \mathrm{mM}, 3 \mu$ lof Water, $2 \mu 1$ of Purified extract) according to the following program: $96^{\circ} \mathrm{C}$ for 3 minutes, $96^{\circ} \mathrm{C}, 55^{\circ} \mathrm{C}$ for $15 \mathrm{sec}, 60^{\circ} \mathrm{C}$ for 4 minutes, $60^{\circ} \mathrm{C}$ for 10 min over 25 cycles. The resulting PCR products underwenta membrane filtration using the Edge BIO kit and then through the Hitachi ${ }^{\circledR} 3130$ Genetic Analyzer Applied Biosystems Sequencer. The sequences obtained were transferred to a computer for analysis. The sequencesediting was done using 4 peaks ${ }^{\circledR}$ software and the sequences were subjected to comparison by blastx (www.ncbi.nim.nih). The comparison results were selected on the basis of 97$100 \%$ identity.

Molecular characterization was performed at Bacteriology-Hygiene Laboratory of Bicêtre Hospital in Paris.

\section{Results}

\section{Antibiotic susceptibility}

The different bacteria were all resistant to amoxicillin. Only a few (2.1\%) were susceptible to levofloxacin and sulfamethoxazole-trimetroprime beta-lactamase inhibitors. Cefepime and cefoxitin resistance rates were respectively $95.6 \%$ and $19.5 \%$. The resistance to gentamicin was $72 \%$ (Figure 1 ). Some cases of resistance to imipenen (6.5\%) and ertapenem (8.7\%) were observed.

\section{Extendum Spectrum Beta-lactamase genes}

All bacteria produced at least one desired beta-lactamase gene. Indeed $97.9 \%(n=45)$ carried bla $a_{\text {CTXM }}$ and / or bla $a_{\mathrm{SHV}}$. bla $a_{\mathrm{CTXM}}$ was carried by 33 strains mean $72 \%$; all E. coli strains were positive to bla $a_{\mathrm{CTXM}}$. All the strains of $K$. pneumoniae $(\mathrm{n}=20)$ carried one type of bla $a_{\mathrm{SHV}}$ and for eight $(08)$ of them, which is $40 \%$ it was associated with $b / a_{\mathrm{CTXM}}$. One strain of E. cloacae was negative to both genes despite the phenotypic presence of a synergistic image between the molecule of aztreonam and that of amoxicillin + clavulanic acid. For the latter we performed an amplification of the bla $a_{\text {TEM }}$ gene which was positive

(Figure 2). At sequencing, all bla $a_{\mathrm{CTXM}}$ genes identified were $b / a_{\mathrm{CTXM}-15}$ for the 33 positive bla $a_{\mathrm{CTXM}}$ strains. 
Different $b / a_{\mathrm{SHV}}$ were identified. The most found type was $b / a_{\mathrm{SHV}-11}$ in a proportion of $45 \%(\mathrm{n}=9)$. The other types were bla $a_{\mathrm{SHV}-1}(15 \% ; n=3)$, bla $a_{\mathrm{SHV}-28}(20 \% ; n=4)$, bla $a_{\mathrm{SHV}-61}(10 \% ; n=2), b / a_{\mathrm{SHV}-77}(10 \% ; n=2)$. On the CTXM-15 combinations, we found $37.5 \%$ bla $a_{\text {SHV }-11}(n=3), 37.5 \% b / a_{S H V-28}(n=3)$ and $25 \% b / a_{S H V}$ ${ }_{1}(\mathrm{n}=2)$. The strains carrying the $b / a_{\mathrm{SHV}-1} / b_{\mathrm{CTXM}-15}$ combination were from INH and had almost the same susceptibility profile except that one was susceptible to gentamicin. Among the three strains carrying the $b / a_{\mathrm{SHV}-11} / b / a_{\mathrm{CTXM}-15}$ Combination, two were from INH, one of which was resistant to cefoxitin and the strain isolated from CHUSO was resistant to ertapenem. The strains carrying the bla $a_{\mathrm{SHV}}$

${ }_{28} /$ bla CTXM-15 $_{15}$ combination all came from INH and only one was susceptible to cefalotin. All these strains were isolated between July and August 2016. Among all the SHVs, only SHV-11 and SHV-77 were identified on strains of both years.

The strain of $E$. cloacae showing a synergistic image but showing neither $b / a_{\mathrm{SHV}}$ gene nor $b / a_{\mathrm{CTXM}-15}$ was positive for the amplification of the bla $a_{\mathrm{TEM}}$ gene. At sequencing, $b / a_{\mathrm{TEM}-1 \mathrm{~b}}$ was found with $99 \%$ identity with strain S86b (GenBank Accession number JF910132)

The different distributions of the genes are in Table 1.

\section{Discussion}

In this study, different antibiotic susceptibilities were noted. Indeed ESBL confers resistance to all betalactams except cefoxitin and carbapenems and their action is inhibited by beta-lactamase inhibitors such as clavulanic acid. We found that our strains show relatively little susceptibility to amoxicillin + clavulanic acid combination and $19.5 \%$ of the strains were resistant to cefoxitin, suggesting a combination of mechanisms. Indeed for some (8.5\%), we have a resistance to carbapenems which may explain the insensitivity to inhibitors. Resistance to cefoxitin to some extent may be explained by overexpression of the natural cephalosporinase in $K$. pneumoniae and E. cloacae. In all cases, these strains are multidrugresistant, as most, $72 \%$, and $98 \%$ are resistant to gentamicin, to sulfamethoxazole-trimetoprim and to levofloxacin, respectively. This multi-resistance was also observed in Senegal (5), Nigeria (7) on strains producing an ESBL and even here in Togo since 2009 (6). Extended spectrum beta-lactamases are disseminated throughout the world. So it is not surprising that we constantly find it in our laboratories of medical bacteriology.

The exclusive presence of bla $a_{\mathrm{CTXM}-15}$ on all $E$. coli and $40 \%$ of $K$. pneumoniae strains, and two-thirds of $E$. cloacae strains over these two years suggest a dissemination at the level of the city. Indeed, INH is a laboratory that receives samples from both the urban community and some private clinics in the city and the laboratory of Sylvanus Olympio Teaching Hospital deals exclusively with samples from inpatients or outpatients. bla $a_{\mathrm{CTXM}-15}$ is a common gene in Enterobacteriaceae especially E. coli and Klebsielles. It was already identified on enterobacterial strains in Senegal, Angola, Ghana, Nigeria and Burkina Faso (8-11), which are countries of the sub-region. Additional studies are needed to determine if this is the same clone circulating in the sub-region. 
$\mathrm{SHV}$ is a constitutive beta-lactamase in K. pneumoniae. The first to be described is SHV-1 (3) and since then several variants exist that are either ESBL or not (12). All variants described in our study were all ESBL and some associated with CTXM-15 (www.bldb.eu; https://www.card.ca). The identification of different types of SHV shows us a diversity of circulation of K. pneumoniae strains in Lomé. Two types remain dominant: $b / a_{\mathrm{SHV}-1}$ and $b / a_{\mathrm{SHV}-11}$ identified in total over $60 \%$ of the strains. Indeed $b / a_{\mathrm{SHV}-11}$ is a variant of bla $a_{\mathrm{SHV}-1}$ with a slight amino acid substitution (12). These two types were also prevalent in Korean hospitals in 2002 (13). In Senegal, however, they had identified SHV-2 and SHV-12 on Salmonella strains from 1999 to 2001 (8).

In our study, two other types: SHV-1 and SHV-77 were described on strains in both years suggesting a probable expansion of the same strains.

The association of two types of ESBL as described in our study indicates an exogenous acquisition by transfer of genetic elements. Since most ESBL plasmids are known to carry other antibiotic resistance genes, it is easy to understand the multi-resistance of the strains in this study. b/a $a_{\mathrm{SHV}-28} / \mathrm{b} / a_{\mathrm{CTXM}-15} \mathrm{Was}$ described on strains of $K$. pneumoniae isolated in Copenhagen, Denmark as being an epidemic clone (14). This association was found in 3 strains isolated between July and August 2016 also making us think of this same hypothesis. However this is to be confirmed by genotypic techniques.

Two of the K. pneumoniae strains carried the bla $a_{\mathrm{SHV}-61}$ gene, which was first described in 2009 in Portugal. They were isolated in June and July of the same year in pus from different patients. Without further information on patients, we were unable to investigate the notion of recent or past travel in this country.

bla $a_{\text {TEM }}$ is a beta-lactamase that was already described in isolates of Escherichia coli and K. pneumoniae in our country $(15,16)$. Its presence on an isolate of Enterobacter cloacae remains a first in our country.

The prevalence of carbapenem resistance in this study is low. Indeed, carbapenems are molecules used as a last resort for the treatment of infections due to ESBL or multidrug-resistant bacteria. The existence of some carbapenem-resistant bacteria requires a better understanding of the mechanisms underlying this resistance.

\section{Conclusions}

During our study, we noticed a multi-resistance of the various strains isolated. The extended spectrum beta-lactamase genes carried by the strains in the two laboratoriesin Lomé are quite diverse $\left(b / a_{\mathrm{TEM}}\right.$, $\left.b / a_{\mathrm{SHV}}, b / a_{\mathrm{CTXM}}\right)$. Indeed, there is a diversity of $b / a_{\mathrm{SHV}}$ on strains of Klebsiella pneumoniae, on the other hand, b/a $a_{\text {СТХM-15 }}$ remains dominant on the strains of Escherichia coli as well as on those of $K$. pneumoniae, bla $a_{\mathrm{TEM}}$ would seem to be the ESBL to look for in case of negativity of the two previous ones. 
The existence of certain genes combinations on several isolates of our study suggests a clonal expansion and therefore strategies must be put in place to avoid probable epidemics.

\section{Abbreviations}

ESBL: Extendum Spectrum Betalactamase,CHU: Centre Hospitalier Universitaire,CHUSO : Centre Hospitalier Universitaire Sylvanus Olympio,INH : Institut National d'Hygiène.

\section{Declarations}

Ethics approval and consent to participate: Not applicable Consent for publication: Not applicable

Available of data and material: The datasets used and/or analysed during the current study are available from the corresponding author on reasonable request.

Competing interest: Authors declare that they have no competing interests

Funding: Not applicable

Authors contributions: This is a collaborative study done with all authors: DS design and conducted the study, wrote protocol and manuscript; IWM, PDM, DAY, SM helped in protocol writing, read and approved final manuscript; GAM, KBA, BB, AE gave assistance for having strains for each facility.

Acknowlegments: We are thankfull to all the staff of UA:7361 in Bicêtre Hospital Bacteriology- Hygiene Laboratory who helped us to do molecular characterisation.

Author's information : Sika DOSSIM ;Tel : +228 91287759; E-mail : sikorlaure@gmail.com

\section{References}

1. Cantón R, González-Alba JM, Galán JC. CTX-M Enzymes: Origin and Diffusion. Front Microbiol [Internet]. 2 avr 2012 [cité 15 oct 2016];3. Disponible sur: http://www.nc\{Citation\}bi.nlm.nih.gov/pmc/articles/PMC3316993/

2. Isikgoz Tasbakan M, Durusoy R, Pullukcu H, Sipahi OR, Ulusoy S. Hospital-acquired urinary tract infection point prevalence in Turkey: Differences in risk factors among patient groups. Ann Clin Microbiol Antimicrob. 4 nov 2013;12:31.

3. Chaves J, Ladona MG, Segura C, Coira A, Reig R, Ampurdanés C. SHV-1 $\beta$-Lactamase Is Mainly a Chromosomally Encoded Species-Specific Enzyme in Klebsiella pneumoniae. Antimicrob Agents Chemother. 1 oct 2001;45(10):2856-61.

4. Abejew AA, Denboba AA, Mekonnen AG. Prevalence and antibiotic resistance pattern of urinary tract bacterial infections in Dessie area, North-East Ethiopia. BMC Res Notes [Internet]. 3 oct 2014 [cité 17 
août 2016];7. Disponible sur: http://www.ncbi.nlm.nih.gov/pmc/articles/PMC4195856/

5. Sangare SA, Maiga Al, Guindo I, Maiga A, Camara N, Savadogo S, et al. Prevalence of extendedspectrum beta-lactamase-producing Enterobacteriaceae isolated from blood cultures in Africa. Médecine Mal Infect. 1 sept 2015;45(9):374-82.

6. Salou M., Assimadzi B., Wateba I.M., Dossim S., Tigossou S.D., Dagnra A.Y., et al. Résistance aux antibiotiques des bactéries isolées en 2009 au laboratoire de bactériologie du CHU- Tokoin de Lomé. J Rech Sci Univ Lomé. 2011;151-9.

7. Azekhueme I, Moses A, Abbey S. Extended Spectrum Beta-Lactamases in Clinical Isolates of Escherichia coli and Klebsiella pneumoniae from University of Uyo Teaching Hospital, Uyo-Nigeria. J Adv Med Pharm Sci. 10 janv 2015;2(3):117-25.

8. Harrois D, Breurec S, Seck A, Delauné A, Hello SL, Gándara MP de la, et al. Prevalence and characterization of extended-spectrum $\beta$-lactamase-producing clinical Salmonella enterica isolates in Dakar, Senegal, from 1999 to 2009. Clin Microbiol Infect. 1 févr 2014;20(2):0109-16.

9. Ouedraogo A-S, Sanou M, Kissou A, Sanou S, Solaré H, Kaboré F, et al. High prevalence of extendedspectrum ß-lactamase producing enterobacteriaceae among clinical isolates in Burkina Faso. BMC Infect Dis [Internet]. 11 juill 2016 [cité 21 août 2017];16. Disponible sur: http://www.ncbi.nlm.nih.gov/pmc/articles/PMC4939587/

10. Ribeiro TG, Novais Â, Peixe L, Machado E. Atypical epidemiology of CTX-M-15 among Enterobacteriaceae from a high diversity of non-clinical niches in Angola. J Antimicrob Chemother. 1 mai 2016;71(5):1169-73.

11. Soge 00, Queenan AM, Ojo KK, Adeniyi BA, Roberts MC. CTX-M-15 extended-spectrum $\beta$-lactamase from Nigerian Klebsiella pneumoniae. J Antimicrob Chemother. 1 janv 2006;57(1):24-30.

12. Liakopoulos A, Mevius D, Ceccarelli D. A Review of SHV Extended-Spectrum $\beta$-Lactamases: Neglected Yet Ubiquitous. Front Microbiol [Internet]. 5 sept 2016 [cité 15 oct 2016];7. Disponible sur: http://www.ncbi.nlm.nih.gov/pmc/articles/PMC5011133/

13. Lee $\mathrm{YH}$, Cho B, Bae IK, Chang $\mathrm{CL}$, Jeong SH. Klebsiella pneumoniae strains carrying the chromosomal SHV-11 $\beta$-lactamase gene produce the plasmid-mediated SHV-12 extended-spectrum $\beta$-lactamase more frequently than those carrying the chromosomal SHV-1 $\beta$-lactamase gene. J Antimicrob Chemother. 1 juin 2006;57(6):1259-61.

14. Nielsen JB, Skov MN, Jørgensen RL, Heltberg O, Hansen DS, Schønning K. Identification of CTX-M15-, SHV-28-producing Klebsiella pneumoniae ST15 as an epidemic clone in the Copenhagen area using a semi-automated Rep-PCR typing assay. Eur J Clin Microbiol Infect Dis Off Publ Eur Soc Clin Microbiol. juin 2011;30(6):773-8.

15. Salah Fortune D., Diagbouga Serge, Dabire Amana M., Sadji Adodo Y., Nadembega Christelle, Moumouni Aissatou, et al. First dectection of resistance genes encoding extended spectrum Beta lactamase producting Escherichia coli at Lomé, Togo. Arch Clin Microbiol. 2016;7(6:32):7p.

16. Diagbouga Serge, Salah Fortune D., Sadji Adodo Y., Dabire Amana M., Nadembega Christelle, Banla Kere Abiba, et al. Detection of high prevalence of TEM/SHV/CTX-M genes in ESBL producing and 
multidrug resistant Klebsiella pneumoniae and Klebsiella oxytoca. J Clin Diagn Res. 4(1):7p.

\section{Tables}

Table 1: Distributions of the different genes identified

\begin{tabular}{cllll}
\hline & & bla $_{\text {CTXM-15 }}$ & bla $_{\text {TEM-1b }}$ & Total \\
\hline & Effectif & 25 & 1 & 26 \\
\hline bla $_{\text {SHV }-1}$ & 1 & 2 & 0 & 3 \\
\hline bla $_{\text {SHV-11 }}$ & 6 & 3 & 0 & 9 \\
\hline bla $_{\text {SHV-28 }}$ & 1 & 3 & 0 & 4 \\
\hline bla $_{\text {SHV-61 }}$ & 2 & 0 & 0 & 2 \\
\hline bla $_{\text {SHV-77 }}$ & 2 & 0 & 0 & 2 \\
\hline Total & 12 & 33 & 1 & 46
\end{tabular}

Figures 


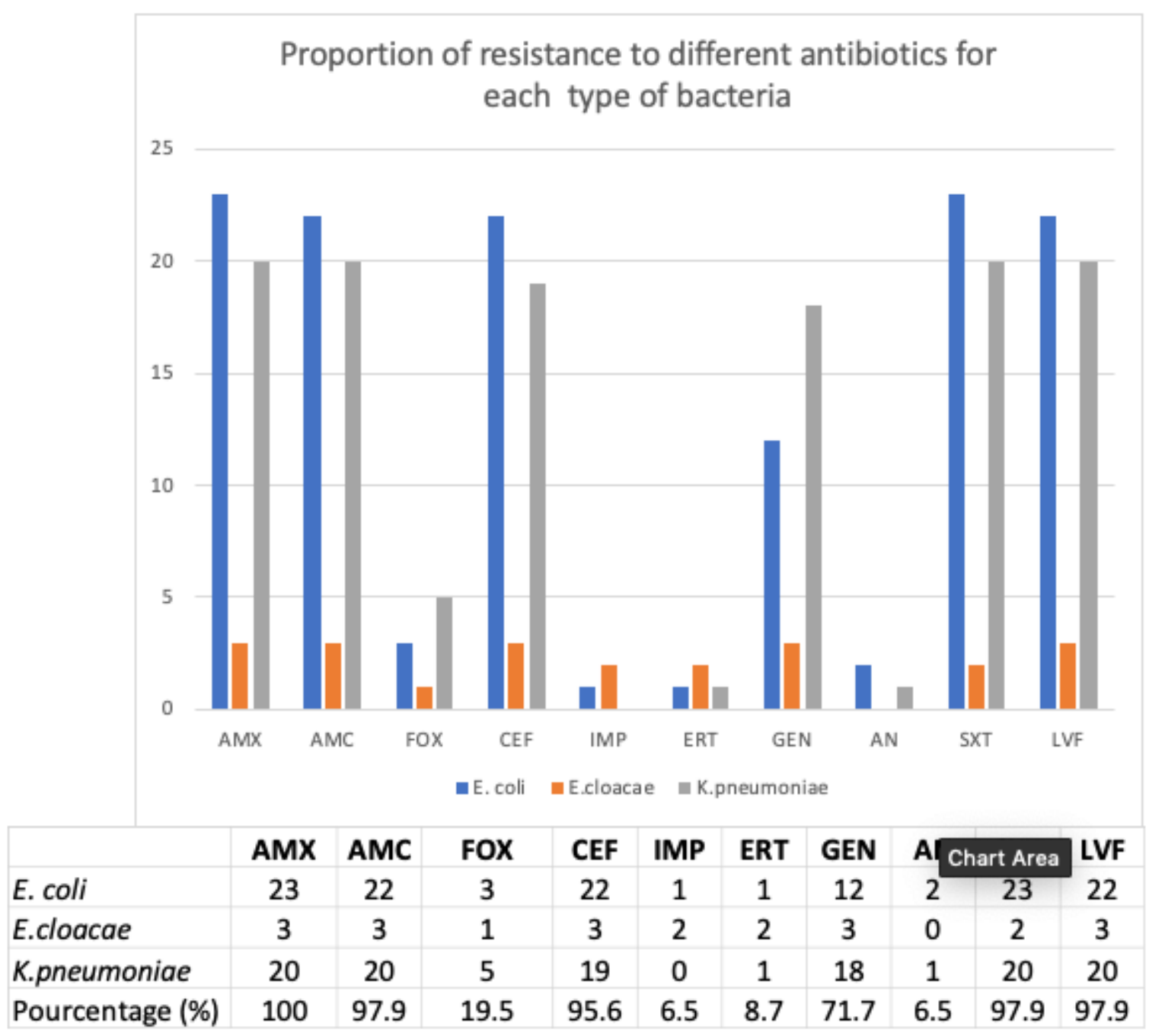

Figure 1

Proportion of resistance to different antibiotics for each type of bacteria AMX : amoxicillin, AMC : amoxicillin+acid clavulanic, FOX : cefoxitin, CEF : cefepime, IMP : imipenem, ERT: ertapenem, GEN: gentamicin, AN: amikacine, SXT: suldadoxin+trimethoprim, LVF: levofloxacin. 


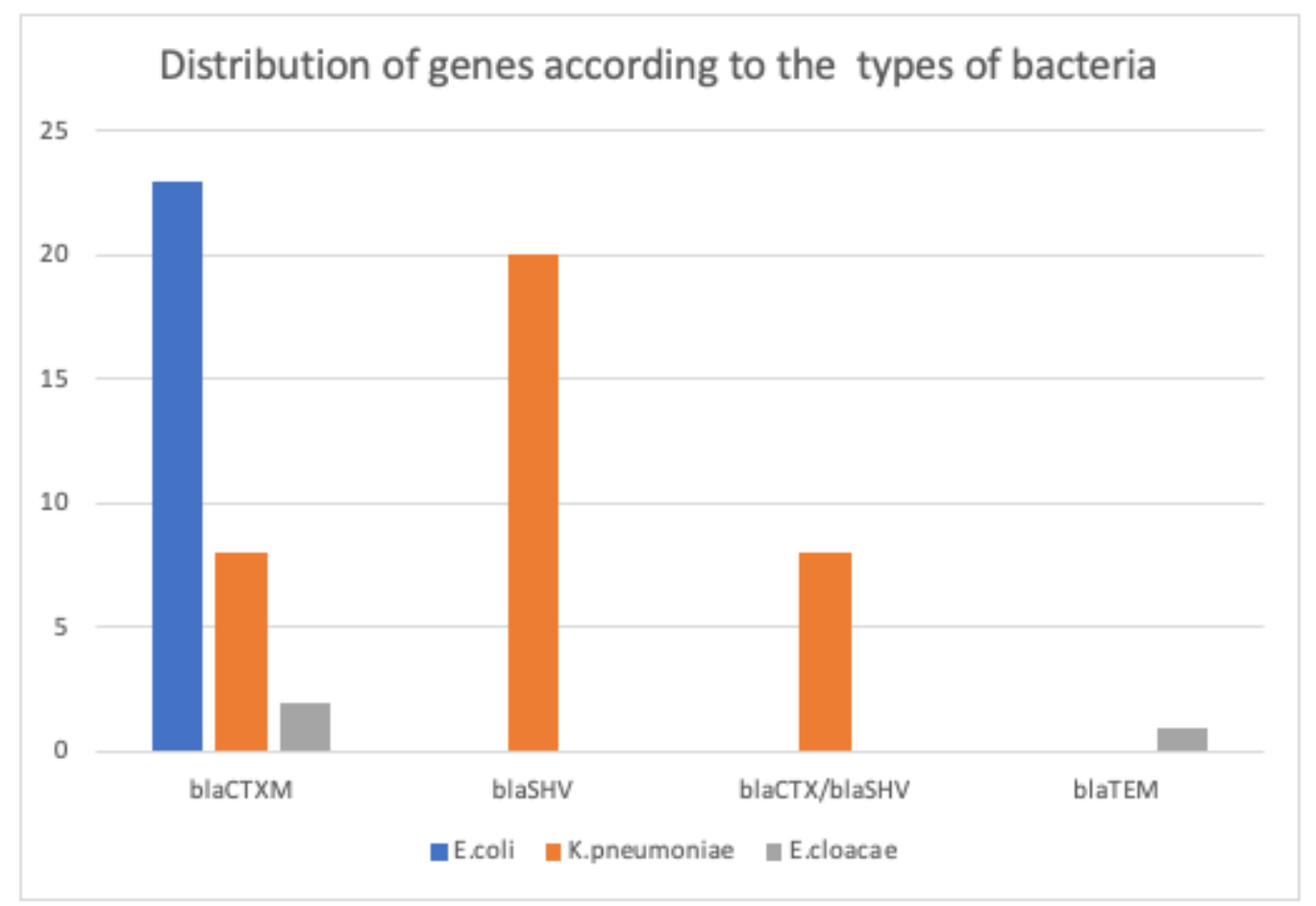

Figure 2

Distribution of the genes identified according to the types of bacteria. 